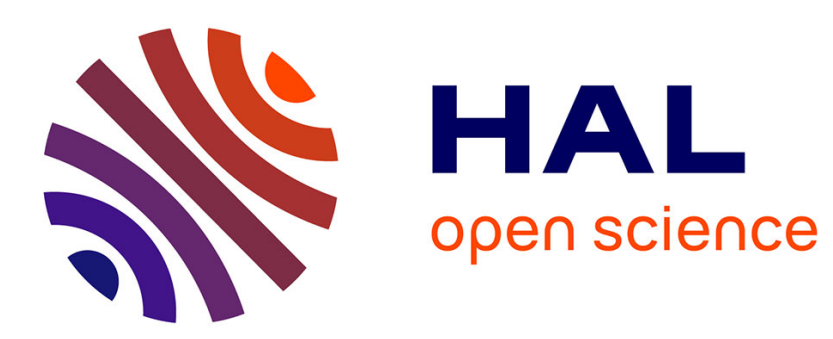

\title{
Definition of lower boundary in region of strength joints at high rate of strain of metals
}

\author{
Yu Besshaposhnikov, V. Chernukhin, V. Kozhevnikov, V. Pai
}

\section{To cite this version:}

Yu Besshaposhnikov, V. Chernukhin, V. Kozhevnikov, V. Pai. Definition of lower boundary in region of strength joints at high rate of strain of metals. Journal de Physique IV Proceedings, 1994, 04 (C8), pp.C8-539-C8-545. 10.1051/jp4:1994884 . jpa-00253445

\section{HAL Id: jpa-00253445 https://hal.science/jpa-00253445}

Submitted on 1 Jan 1994

HAL is a multi-disciplinary open access archive for the deposit and dissemination of scientific research documents, whether they are published or not. The documents may come from teaching and research institutions in France or abroad, or from public or private research centers.
L'archive ouverte pluridisciplinaire HAL, est destinée au dépôt et à la diffusion de documents scientifiques de niveau recherche, publiés ou non, émanant des établissements d'enseignement et de recherche français ou étrangers, des laboratoires publics ou privés. 


\title{
Definition of lower boundary in region of strength joints at high rate of strain of metals
}

Yu Besshaposhnikov, V. Chernukhin, V. Kozhevnikov and V. Pai

PA "Uralkhimmash", 620010 Ekaterinburg, Russia

\begin{abstract}
Resumé: On a défini expérimentalement les régions du soudage à l'aide de l'explosion pour obtenir une série de joints bimétalliques à la solidité non moindre que celle du materiau le plus faible. Pour la construction correcte des régions du soudage on a exploré l'influence des faits suivants: la dépendance de l'indice de polytropie des produits de l'explosion vis-a-vis de la vitesse de la détonation; l'influence de la pression résiduelle des produits de la détonation; les distortions périphériques au moment du lancement de la plaque; l'influence de la résistance des matériaux sur la géometrie de l'impact des plaques. On a proposé des rapports mathématiques pour le calcul de la limite inférieure des régions du soudage, la pression optimum résiduelle des produits de la détonation, la dimensions de la zone des effets périphériques et de l'indice de polytropie.
\end{abstract}

\begin{abstract}
Explosive weldability windows were determined by means of experiments to obtain bimetallic joints with strength not less than that of the weaker material. To construct the weldability window correctly the influence of factors not previously taken into account has been investigated. These factors are the dependence of the polytropic exponent of the explosion products on detonation velocity, the periphery distortions under casting of the plate and the influence of material strength on the plate collision geometry. Mathematical relations to calculate the lower boundary of the weldability window, the optimum residual pressure, the dimensions of the zone of periphery effects and the polytropic exponent have been developed.
\end{abstract}

\section{INTRODUCTION}

Properties of metals at the high rates of strain due to explosive welding define to a great extent the quality of the welded joint. Determination of collision parameters to give a joint of high strength is also important. These parameters are usually determined experimentally in terms of the $V_{k}-\gamma$ diagram, where $V_{k}$ is the collision point velocity and $\gamma$ is the impact angle. The region on this diagram corresponding to welded joints of satisfactory strength, as determined experimentally, is usually called the "weldability window". The lower boundary of this region corresponds to the minimum satisfactory values of $V_{k}$ and $\gamma$. A knowledge of these minimum values, therefore, is very important in practice. Unfortunately existing procedures for defining this lower boundary [1-3] have not always given satisfactory results because of quite a number of unsolved problems. 
When defining the impact angle $\gamma$, see fig. 1 , it is essential to know $K$, the polytropic exponent of the detonation products. Nowadays this is unknown for quite a number of low rate explosives in current use. Unfortunately a constant value cannot be given to the $K$ exponent $[4,5]$ since fall in detonation velocity causes a decrease in $K$. This should be taken into account when calculating $\gamma$. Lack of a precise criterion for finding the zone of periphery distortions in the casting plate because of rarefaction waves

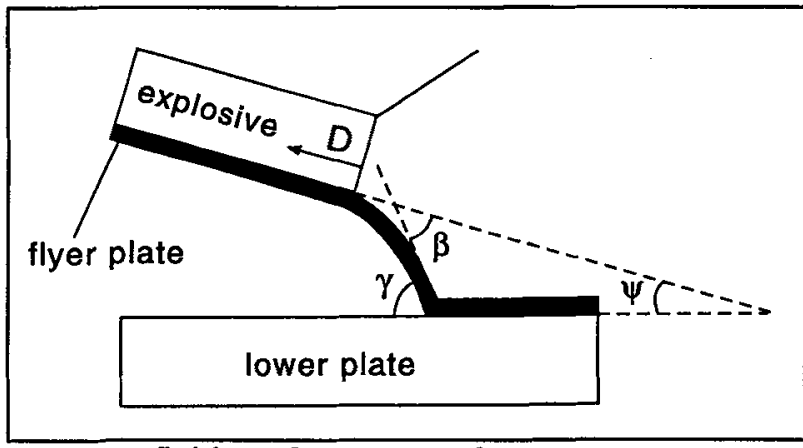

Fig. 1 Definition of Impact Angles from the edges of the charge makes it impossible to choose optimal overhang dimensions so as to eliminate periphery effects which also affect $V k$ and $\gamma$. Recommendations given in [6] do not ensure adequate results. The question of the influence of the strength on the plate collision geometry for explosive welding $[1,2,7,8]$ is far from being understood and additional study is necessary to determine the extent of its effect.

Finally practice shows that when attempting to weld pairs of metals which do not weld easily or when the pieces being welded are large significant factors determining the joint quality are the magnitude and duration of the residual pressure of the detonation products in the joint zone [2]. Residual pressure also affects the time of appearance of tensile stresses capable of breaking the joint before its complete formation [2]. As a result it became necessary to investigate the effect of residual stresses on the weldability window.

Thus to achieve a more correct determination of the lower boundary of the weldability window, this study attempts to solve the above mentioned problems, observed in scientific experiments, so allowing the development of commercial technologies in explosive welding.

\section{METHOD OF DETERMINATION OF EXPLOSIVE WELDING PARAMETERS AND FACTORS AFFECTING THE LOWER BOUNDARY OF THE WELDABIIITY WINDOW}

\subsection{Determination of $\mathrm{K}$}

Since the location of a gauge in the gap may disturb the collision between the plates being explosively welded parameters $V_{k}$ and $\gamma$ were determined in the following way. Firstly experimental measurements of the curved profile of the explosively driven flyer plate (the profile of casting) were compared with those computed using a two-dimensional model $[1,2]$. Hence the mean (effective) polytropic exponent $\mathrm{K}$ could be determined for different values of $\mathbf{D}$ and $\mathbf{r}$ (where $D$ is the detonation rate and $\mathbf{r}$ is the ratio of the mass of the explosive to that of the plate) by using different mixed explosives. Then, taking the appropriate value of $K$, the bend angle, $B$, see fig. 1 , for the impact of an explosively driven flyer plate with an initially parallel lower plate, was computed, again using the two-dimensional model [1,2], for flyer and lower plate thicknesses, $\delta_{1}$ and $\delta_{2}$, ranging from 1 to $30 \mathrm{~mm}$ and 1 to $100 \mathrm{~mm}$, respectively. In this case $B$ is equal to $\gamma$.

Since $V_{\boldsymbol{K}}=\mathbf{D}$, determination of $V_{\boldsymbol{k}}$ presented no problems. Standard methods, employing contact gauges and high frequency chronometers with a maximum error of $2 \%$, were used to measure $\mathrm{D}$ and determine $K$. The slanted resistance wire technique [1,4], as shown in fig. 2, was used to determine the profile of casting. Dimensionless coordinates, $\mathbf{X}$ and $\mathbf{Y}$, given by 


$$
X=\left(\frac{D \cdot t}{H}\right)+L_{g} \cdot\left(\frac{\cos \alpha}{H}\right) \text { and } Y=L_{g} \cdot\left(\frac{\sin \alpha}{H}\right)
$$

where $t$ is time, determined from an oscillogram, see fig. $2 b, L_{g}$ is the length of the closed part of the resistance wire gauge, $H$ is the thickness of the explosive charge and $\alpha$ is the angle of the resistance wire gauge (see fig. 2). The error in the determination of the coordinates by this method did not exceed $5 \%$. Thus both $B$ and $\mathrm{Vc}$, the absolute velocity at which the given point on the profile was approaching the lower plate, could easily be calculated. Hence it was established for the first time [4] that $K$, determined in this way, depended on $D$.
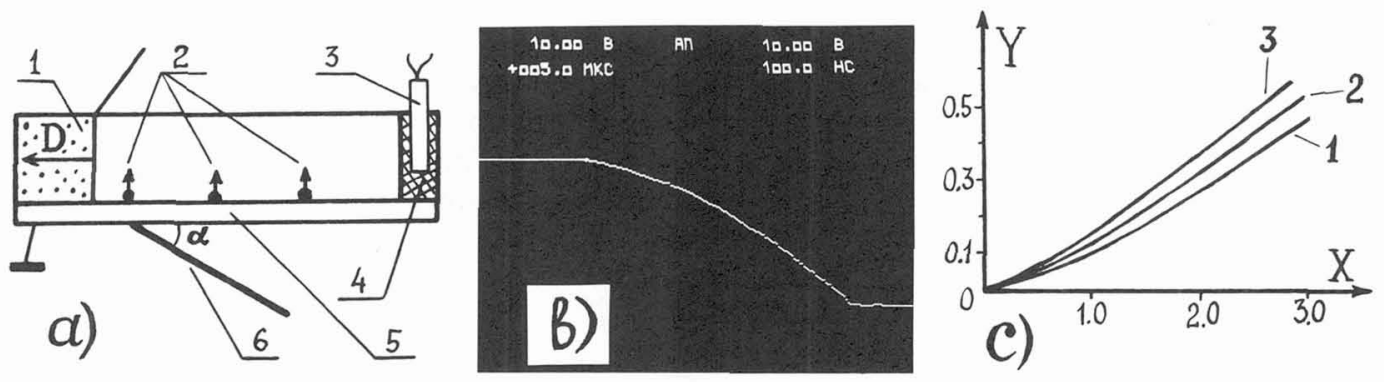

Fig. 2 Measurement of the Profile of the Flyer Plate

a) Experimental set-up ( 1 - explosive; 2 - contact gauges to measure value of $\mathrm{D} ; 3$ - detonator; 4 - plane initiator; 5 - flyer plate; 6 - resistance gauge)

b) Typical oscillogram of resistance gauge signal

c) Typical calculate plate profiles using AT-1 explosive at $r=1.0(1-\mathrm{D}=2500 \mathrm{~m} / \mathrm{s}, \mathrm{K}=2.5 ; 2$

- $\mathrm{D}=2160 \mathrm{~m} / \mathrm{s}, \mathrm{K}=2.4 ; 3-\mathrm{D}=1550 \mathrm{~m} / \mathrm{s}, \mathrm{K}=2.2$ )

A more detailed approach to this problem showed that the dependence of $K$ on $D$ could be represented by the empirical relation

$$
\kappa=C \cdot \arctan \left(\frac{D^{3}}{A}+\frac{D^{2}}{B}\right)^{2}
$$

where $\mathbf{D}$ is in $\mathrm{km} / \mathrm{s}$ and $\mathbf{A}, \mathbf{B}$, and $\mathbf{C}$ are coefficients depending on the type of explosive. Errors in the calculation of $\mathrm{Y}$ in terms of equation (3) did not exceed $8 \%$.

\subsection{Determination of Periphery Effects}

The curved profile of the explosively driven flyer plate was determined in three different peripheral regions, that associated with the early stages of the process (initial zone), see fig. $3 \mathrm{a}$, that associated with the lateral regions of the plate, see fig. $3 \mathrm{~b}$, and that associated with the later stages of the process (end zone), see fig. 3c. Again the method was based on the use of resistance gauges located under the plate and arranged, in this case, in the most suitable array for the region being studied. The oscillogram records were synchronised to a single time origin and appropriate mathematical expressions were used to obtain the coordinates of the points of intersection between the flyer plate and the resistance gauges, thereby allowing the curved profile of the flyer plate in these regions to be determined at any given point in time. Typical results in the periphery regions are illustrated in fig. 3.

Similar results for the dependence of the kinematic parameters, $\mathbf{V k}, \mathbf{V c}$ and $\boldsymbol{\gamma}$ on position in the 

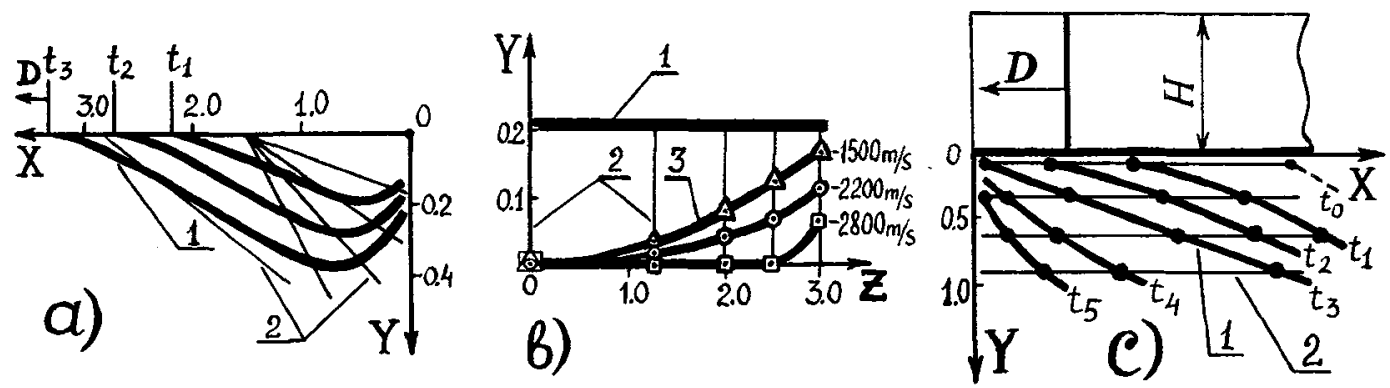

Fig. 3 Measurement of the Profile of the Flyer Plate in the Peripheral Regions

a) Initial zone ( 1 - profile of flyer plate, thick lines; 2 - resistance gauges, thin lines)

b) Lateral zones, $\mathbf{Z}$ axis normal to $[\mathrm{X}, \mathrm{Y}]$ plane ( 1 - initial position of flyer plate; $\mathbf{2}$ - positions of resistance gauges; 3 - profiles of flyer plate)

c) End zone ( 1 - profile of flyer plate at time $t_{3}$, thick line; 2 - positions of resistance gauges, thin lines)
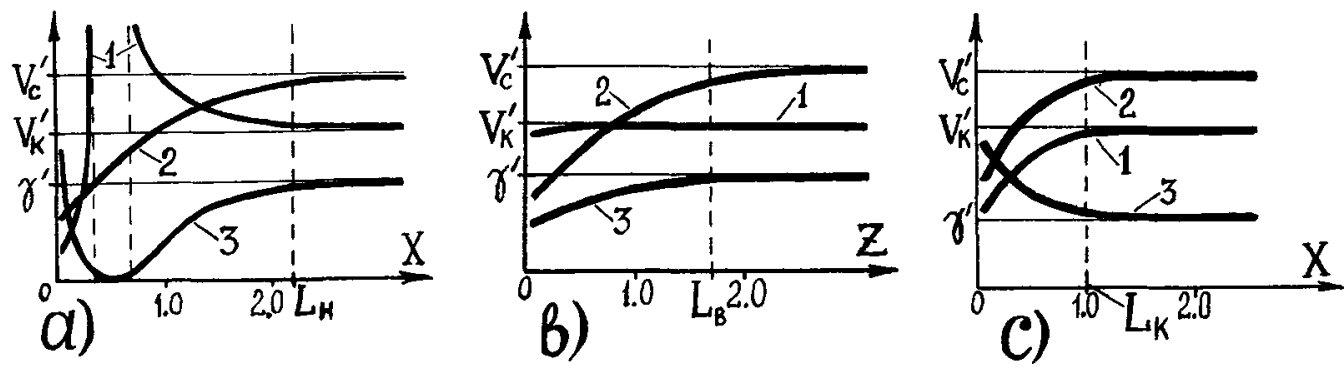

Fig. 4 Dependence of the Kinematic Parameters on Position in the Peripheral Zones $\left(V^{\prime}, V^{\prime}\right.$ and $\gamma^{\prime}$ are the values of the parameters not affected by peripheral rarefaction waves) a) Initial and c) End Zones ( 1 - Vk vs $X ; 2$ - Vc vs $X ; 3$ - $\gamma$ vs $X)$ b) Lateral Zone (1 - Vk vs Z; 2 - Vc vs Z; 3 - $\gamma$ vs Z)

three peripheral zones are given in fig. 4. These show that the process is essentially unstationary in the initial and end zones, figs. $4 a$ and $c$, while in the lateral zones beyond a certain $Y$ acceleration distance the kinematic parameters are independent of time. It was shown in fig. $3 \mathbf{b}$ that the extent of the lateral zone decreased with increasing $\mathbf{D}$ while the extent of the initial and end zones, figs. $3 a$ and $c$, was related to the $\mathbf{Y}$ acceleration distance. By analysing the experimental data the following empirical relations were obtained

$$
L_{H}=\left(1.9+\frac{Y}{0.63}\right) \cdot H ; L_{B}=[(D *-D) \cdot \tan \phi] \cdot H ; L_{K}=\left(\frac{Y . H}{\tan \gamma}\right)
$$

where $L_{H}, L_{B}$ and $L_{K}$ are the initial, lateral and end overhangs, respectively, $\phi=60^{\circ}, D^{*}=3.2 \mathrm{~km} / \mathrm{s}$, and $D$ lies between 1.5 and $3.0 \mathrm{~km} / \mathrm{s}$. For an approximate calculation of $B$ the formula

$$
\beta=\left(\frac{\pi}{2}\right)\left(\sqrt{\left(\frac{k+1}{k-1}\right)}-1\right) \cdot\left(\frac{r . Y}{(r+2.72) Y+0.184}\right)
$$

can be used $[1,2]$. These allow a sufficiently accurate determination to be made of the size of the various peripheral zones and of the flyer plate overhangs in terms of D, Y and $\gamma$. 


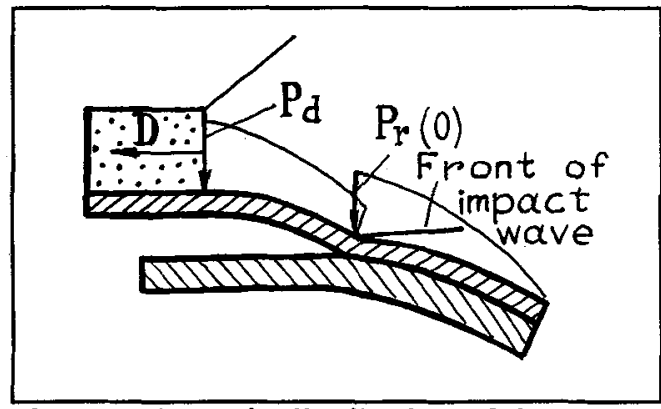

Fig. 5 Schematic distribution of detonation product pressure on flyer plate

\subsection{Determination of Residual Pressure Effects}

In studying residual pressure effects the residual pressure was characterised by its peak value, $P_{r}(0)$, as calculated using the two-dimensional model [1] and taking into account the second bend of the flyer plate at which point the oblique nature of the impact wavefront results in additional compression and supersonic flow of the detonation products, see fig. 5 where $P_{d}$ is the detonation pressure and $P_{r}(0)$ is the pressure at the collision point where the shock wave makes oblique impact.

The use of $P_{r}(0)$ to characterise the residual pressure is justified experimentally. The resistance wire technique was used to determine the flyer plate profiles for two tests in which an aluminium flyer plate $\left(\delta_{1}=10 \mathrm{~mm}\right)$ impacts an aluminium lower plate $\left(\delta_{2}=2 \mathrm{~mm}\right)$. In both tests $\mathrm{H}=70 \mathrm{~mm}$ and $D=3.1 \mathrm{~km} / \mathrm{s}$. In the first test $Y . H=1.5 \mathrm{~mm}$ and in the second $20 \mathrm{~mm}$ and in both a strong joint was formed between the two plates. Taking into account the low strength of the aluminium $\left(S_{y}=40 \mathrm{MPa}\right)$ and the small thickness of the lower plate compared with that of the flyer plate it was assumed that the profile of the two-layer system could be exactly described by the equation of motion derived from the previous model [1], taking the two plates as a set of disbonded elements with densities of $\rho_{1}$ and $\rho_{2}$ for the flyer and base plates respectively and giving the equation

$$
\left(\frac{\frac{d^{2} Y}{d X^{2}}}{1+\left(\frac{d Y}{d X}\right)^{2}}\right)^{3 / 2}=\left(\frac{P r \cdot H}{\left(\rho_{1} \cdot \delta_{1}+\rho_{2} \cdot \delta_{2}\right) \cdot D^{2}}\right)
$$

Using this equation and the $Y=Y(X)$ profiles determined experimentally the variation of $P_{r}$ vs $t$ may be obtained, see fig. 6 , from which it was established that the duration of the pressure loading was approximately proportional to the peak residual pressure.

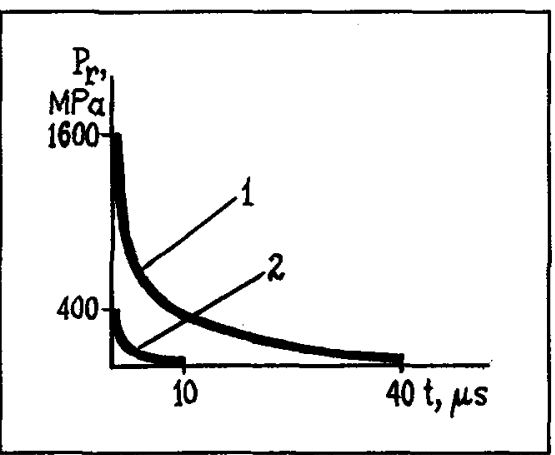

Fig. 6 Plot of $P_{r} v s t$

$(1-\mathrm{Y} . \mathrm{H}=1.5 \mathrm{~mm} ; 2$ - Y.H $=20 \mathrm{~mm})$

To evaluate the influence of the peak residual pressure on the size of the weldability window experiments were carried out on hard weldable metals such as aluminiumsteel and titanium-steel [10-12], both for $P_{r}(0) \approx 0$ and for $P_{r}(0)>0$. Results for titanium-steel, see fig. 7, where $\mathbf{V K}^{\min }$ and $\mathbf{V K}^{\max }$ are limits of welding region broadening on lower boundary, showed that an increase in $P_{r}(0)$ broadened the weldability region at the expense of both the maximum and minimum values of Vk. This compares with aluminium-steel where the broadening of the weldability region was only at the expense of the maximum value of Vk. Experimental data were analysed and an empirical relation developed to evaluate the minimum value of $P_{r}(0)$ for maximum broadening of the weldability window at the expense of an increase in the allowable

range of values for $V_{k}$, giving

$$
P_{x}(0)^{\mathrm{min}}=1 \cdot 35 \cdot\left(S y_{1}+S y_{2}\right)
$$

where $\mathrm{Sy}_{1}$ and $\mathrm{Sy}_{2}$ are the yield stresses for the flyer and lower plate materials, respectively.

Further experiments [10] showed for plates where $\left(\delta_{1} / \delta_{2}\right) \approx 1$ to broaden the weldability window 
and eliminate any reduction in the real impact angle due to the strength effect being lower than that necessary to obtain a strong joint, explosive welding should be carried out at $\mathbf{P}_{\mathbf{r}}(\mathbf{0})$ $\geq \mathrm{P}_{\mathrm{r}}(\mathbf{0})^{\mathrm{min}}$. However, when welding large workpieces, deviations from the optimum values of the technological parameters may occur so that $P_{r}(0)<P_{r}(0)^{\min }$. In practice, provided $P_{r}(0)$, based on the optimum values of the technological parameters, lies between 1.2 and $1.4 \mathrm{P}_{\mathbf{r}}(0)^{\mathrm{min}}$, deviations in these parameters are unlikely to reduce its actual value below $\mathbf{P}_{\mathbf{r}}(\mathbf{0})^{\mathrm{min}}$.

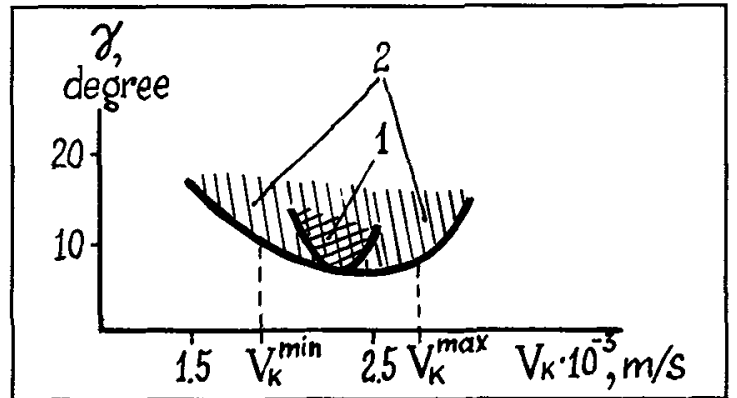

Fig. 7 Weldability window for titanium-steel $\left(1-\mathbf{P}_{\mathbf{r}}(0) \approx 0 ; 2-\mathrm{P}_{\mathbf{r}}(0) \geq \mathrm{P}_{\mathbf{r}}(0)^{\mathrm{min}} ;\right)$

\section{CONCLUSIONS}

On the basis of experimental data for the explosive welding of a wide range of bimetallic combinations with base plates of copper, titanium, aluminium, carbon steel and stainless steel an empirical relation has been developed which allows a determination of the lower boundary of the weldability window that agrees with experimental data to within $10 \%$. This relation has the form

$$
\gamma^{\min }=\frac{\left(n \cdot k_{B} \cdot T\right)}{\left(L^{3} \cdot R \cdot V_{k}\right)}
$$

where $\mathfrak{n}=2.79$ for most materials, the roughness of the welding surfaces lies between 10 and $20 \mu \mathrm{m}, \mathrm{k}_{\mathrm{B}}$ is Boltzman's constant, $\mathrm{T}$ is the lower melting point of the two materials, $\mathrm{L}$ is the closest interatomic spacing in the crystal lattice of the material and $R$, the rated acoustic impedance of the materials to be welded, is given by

$$
R=\frac{\rho_{1} \cdot c_{1} \cdot \rho_{2} \cdot c_{2}}{\left\langle\rho_{1} \cdot c_{1}+\rho_{2} \cdot c_{2}\right\rangle}
$$

where $\rho$ and $c$ are the density and sonic velocity and suffices 1 and 2 refer to the flyer and base plates, respectively. When both materials are alloys it may be difficult to define the appropriate values of $T$ and $L$, in which case the following relations may be used

$$
k_{B} \cdot T \Leftrightarrow \frac{G \cdot L^{3}}{30} \text { or } k_{B} \cdot T \approx \frac{Q}{\left(24 \cdot \Gamma^{2} \cdot X_{C}\right)}
$$

where $G$ is the modulus of shift, $Q$ is the volume of the elementary atomic cell, $\Gamma$ is the Gruneisen constant and $\mathrm{X}_{\mathrm{C}}$ is the coefficient of compressibility. From these results software has been developed to determine the optimum values of the technological parameters for the explosive welding of a wide range of pairs of metals. 


\section{REFERENCES}

1. Deribas, A.A., Physics of Hardening and Welding by Explosion, (Nauka, Novosibirsk, 1980) 8-39, 166-178.

2. Zakharenko, I.D., Welding of Metals by Explosion, (Nauka i technika, Minsk, 1990) 24-30, 60-140.

3. Wittman, R.H., "The influence of collision parameters on the strength and microstructure of an explosion welded aluminium alloy", The Second Intern. Symp. on Explosive Working of Metals, 9-12 October, 1973 (Mariansky Lazny, 1974) 153-168.

4. Besshaposhnikov, Yu.P., Kozhevnikov, V.E., Chernuhkin, V.I. and Pai, V.V., Fizika Goreniya i Vzryva (1984) N4, 129-132.

5. Pyr'ev, V.A. and Solov'ev, V.S., Fizika Goreniya i Vzryva, (1992) N6, 112-116.

6. Krupin, A.V., Solov'ev, V.Ya., Sheftel, N.I. and Kobelev, A.G., "Deformation of metals by explosion", Metallurgiya (Moscow, 1975) 136-152.

7. Prümmer, R.J., "Explosion and explosives, J. Ind. Explosives Soc. of Japan, (1974) N3, 121126.

8. Zhan Kai, Li Lungyuan and Yang Wenbin, "The study of effect of material strength on the motion curve of flyer under glancing detonation", The Sixth Intern. Symp. on Use of Explosive Energy in Manufacturing Metallic materials of New Properties, Gottwaldov, 22-24 October 1985 (Czechoslovak Society for Science and Technology, 1985) 127-133.

9. Baum, F.A., Orlenko, L.P., Stanyukovich, K.P. et al., Physics of Explosion (Nauka, Moscow, 1975) 63-68.

10. Besshaposhnikov, Yu.P., Kozhevnikov, V.E.,Chernukhin, V.I. and Babkov, A.D., "The study of influence of flyer and lower plate thickness on the necessary quantity of a residual pressure peak of detonation products under explosive welding of titanium and steel", Proc. of Scientific Works. Explosive Welding and Properties of Welded Joints, (Volgograd Polytechnical Institute, Volgograd, 1991) 73-86.

11. Besshaposhnikov, Yu.P., Kozhevnikov, V.E. and Chernukhin, V.I., "Obtaining of an explosion welded aluminium +steel bimetal under use of residual pressure of detonation products", Thematic Proc. of Scientific Works. Working of Materials by Impulse Loads (Special Design Office of High-Rate Hydrodynamics, Novosibirsk, 1990) 266-269.

12. Besshaposhnikov, Yu.P., "On role of residual pressure of detonation products under explosive welding of titanium with steel", ibid, 275-281.

13. Chernukhin, V.I., "The periphery effects under explosive welding", ibid, 282-290.

14. Kozhevnikov, V.E., "The definition of the practical explosive welding regions for copper+titanium, copper+aluminium and titanium+aluminium bimetals", ibid, 236-244.

15. Leibfried, G., Gittertheorie der mechanischen und thermischen eigenschaften der kristalle Fizmatgiz (Moscow-Leningrad, 1963) 224,301. 